\title{
The $\mathrm{N}$ - and C-terminal domains of parathyroid hormone-related protein affect differently the osteogenic and adipogenic potential of human mesenchymal stem cells
}

\author{
Antonio Casado-Díaz ${ }^{1,2,3}$, Raquel Santiago-Mora ${ }^{2}$ \\ and José Manuel Quesada ${ }^{1,2,3}$ \\ ${ }^{1}$ SANYRES XXI \\ Córdoba, Spain \\ ${ }^{2}$ Unidad Metabolismo Mineral \\ Hospital Universitario Reina Sofía \\ Avda. Menéndez Pidal s/n \\ 14004 Córdoba, Spain \\ ${ }^{3}$ Corresponding authors: Tel, 34-957010111; \\ Fax, 34-957010111; E-mail, bb1cadia@uco.es (A.C.D), \\ E-mail, md1qugoj@uco.es (J.M.Q) \\ DOI 10.3858/emm.2010.42.2.010
}

Accepted 13 November 2009

Available Online 30 November 2009

Abbreviations: ALP, alkaline phosphatase; LPL, lipoprotein lipase; MSC, mesenchymal stem cell; PTH, parathyroid hormone; PTHrP, parathyroid hormone-related protein

\begin{abstract}
Parathyroid hormone-related protein (PTHrP) is synthesized by diverse tissues, and its processing produces several fragments, each with apparently distinct autocrine and paracrine bioactivities. In bone, PTHrP appears to modulate bone formation in part through promoting osteoblast differentiation. The putative effect of PTH-like and PTH-unrelated fragments of PTHrP on human mesenchymal stem cell (MSCs) is not well known. Human MSCs were treated with PTHrP (1-36) or PTHrP (107-139) or both (each at $10 \mathrm{nM}$ ) in osteogenic or adipogenic medium, from the start or after 6 days of exposure to the corresponding medium, and the expression of several osteoblastogenic and adipogenic markers was analyzed. PTHrP (1-36) inhibited adipogenesis in MSCs and favoured the expression of osteogenic early markers. The opposite was observed with treatment of MSCs with PTHrP (107-139). Moreover, inhibition of the adipogenic differentiation by PTHrP (1-36) prevailed in the presence of PTHrP (107-139). The PTH/PTHrP type 1 receptor (PTH1R) gene expression was maximum in the earlier and later stages of osteogenesis and adipogenesis, respectively. While PTHrP (107-139) did not modify the PTH1R
\end{abstract}

overexpression during adipogenesis, PTHrP (1-36) did inhibit it; an effect which was partially affected by PTHrP (7-34), a PTH1R antagonist, at $1 \mu \mathrm{M}$. These findings demonstrate that both PTHrP domains can exert varying effects on human MSCs differentiation. PTHrP (107-139) showed a tendency to favor adipogenesis, while PTHrP (1-36) induced a mild osteogenic effect in these cells, and inhibited their adipocytic commitment. This further supports the potential anabolic action of the latter peptide in humans.

Keywords: adipogenesis; bone; mesenchymal stem cells; osteogenesis; parathyroid hormone-related protein

\section{Introduction}

Parathyroid hormone-related protein (PTHrP) is the product of a single gene. This, through alternative splicing the multi-exonic PTHrP gene, gives rise to three initial translation products: PTHrP (1-139), PTHrP (1-141), and PTHrP (1-173) (Wysolmerski and Stewart, 1998). These three peptides are identical in positions 1-139 and differ only in their carboxy termini. The three initial PTHrP translation products undergo extensive posttranslational processing and give rise to a family of mature secretory forms of the peptide, each with its own physiological function (s) and each with its own receptor or receptors (Orloff et al., 1994). For example, the amino-terminal PTHrP secretory form, PTHrP (1-36), shares N-terminal homology with PTH and acts through same PTH type 1 receptor (PTH1R) (Juppner et al., 1991); thereby initiating multiple events (e.g. vasorelaxation, bone resorption, cellular proliferation). Mid-region PTHrP appears to have its own cognate receptor (Orloff et al., 1996) and to have different effects, for example, on placental calcium transport. The carboxy-terminal PTHrP peptide, PTHrP (107-139), appears to act through a still different receptor and to have other effects such as inhibition of osteoclastic bone resorption (Fenton et al., 1991).

PTH is considered a key hormone in the regulation of calcium homeostasis in the body, and in contrast to PTHrP, is only produced by the parathyroid glands. However, PTHrP, whose effects are 
mainly autocrine and paracrine, is synthesized by diverse tissues including cartilage and bone (Strewler, 2000). In the latter, PTHrP seems to exert a modulating role on bone formation and remodeling both in the fetus as well as in adults (Miao et al., 2004, 2005).

The anabolic effect of PTH in bone is now well established. Thus, while prolonged exposure to PTH induces bone resorption, its intermittent administration stimulates bone formation (Hock and Gera, 1992). In vitro studies suggest that PTH can affect osteoblast function differently apparently depending on the stage of osteoblast differentiation. In mouse osteoblastic cells and primary cultures of human osteoblast-like cells from bone explants grown in osteogenic medium, PTH induces mineralization when added in a later but not in an earlier time period (Schiller et al., 1999). This anabolic effect of PTH appears to be complex and dependent on Runx2 transactivation (Fujita et al., 2001). Interestingly, daily treatment with PTH (1-34) has been shown to reverse both the decreased expression of osteogenic genes and the increased levels of adipogenic genes, namely peroxisome proliferator-activated receptor (PPAR)- $\gamma$ and lipoprotein lipase (LPL), as shown in the femoral metaphysis of ovariectomized rats (Kulkarni et al., 2007). Moreover, a high PTH (1-34) dose (50 nM) added as a 1-h pulse, but not continuously, to human bone marrow mesenchymal cells was recently found to inhibit their adipogenic commitment (Rickard et al., 2006). These recent data thus suggest that the anabolic effect of PTH could be related at least in part to its capacity to inhibit the adipocytic program in the precursor cells for both osteoblasts and adipocytes. Related to these results using PTH (1-34), in the pre-adipocyte cell line 3T3-L1, the expression of both PTHrP and the PTH1R decreased with adipocyte differentiation, and adipogenesis was inhibited in these PTHrP- overexpressing cells after transfection with a PTHrP cDNA plasmid (Chan et al., 2001). Furthermore, PTHrP (1-34) has been shown to activate osteoblastogenesis and to inhibit adipogenesis in pluripotential mouse C3H10T1/2 cells (Chan et al., 2003).

The C-terminal fragment of PTHrP containing the 107-111 epitope -named osteostatin- is a potent inhibitor of bone resorption in vitro, although its true effect on bone in vivo is unclear (Fenton et al., 1991; Cornish et al., 1997). This PTHrP domain is known to interact with an uncharacterized receptor, but different from the PTH1R in osteoblasts (Valin et al., 1997, 2001; Alonso et al., 2008). It has been previously demonstrated that PTHrP (107-139) can rapidly increase VEGF expression in human osteoblastic cells (Esbrit et al., 2000). In addition, recent studies have shown that its intermittent administration induces various osteogenic effects through interaction with VEGF receptor 2 in these cells (de Gortazar et al., 2006; Alonso et al., 2008). However, the putative effects of this Cterminal PTHrP fragment on human osteoprogenitors are currently unknown.

In the present study, we assessed and compared the effects of the $\mathrm{N}$ - and $\mathrm{C}$-terminal domains of PTHrP on the commitment of human mesenchymal stem cells (MSCs) to either osteoblastic or adipocytic lineages.

\section{Results}

\section{MSCs from human bone marrow can be induced to osteogenesis or adipogenesis}

We first tested the differentiation capacity of our human MSC cultures to the osteogenic or adipogenic lineage. We found that these cell cultures originated from the three bone marrow donors showed a similar capacity to differentiate into osteoblasts or adipocytes in either osteogenic or adipogenic medium, respectively (Figure 1 ). In the presence of osteogenic medium, we found that early markers of osteogenesis, such as ALP activity as well as ALP and runx2 gene expression, showed higher values after 6 days than those at the later times evaluated (Figure 1A). On the other hand, this medium also promoted mineralization of the extracellular matrix, as observed after 24 days of culture by alizarin red staining (Figure 1B, upper panels). The adipogenic medium induced a sharp increase in the expression of both PPAR- $\gamma 2$ and LPL genes, whereas no expression of those genes was detected in control cultures (Figure 1C). Moreover, these cultures accumulated fat vesicles, as shown by oil red staining (Figure 1B, lower panels).

\section{Effect of PTHrP (1-36) and PTHrP (107-139) on osteoblastogenesis in human MSCs}

When human MSCs were treated with PTHrP (1-36) or PTHrP (107-139) at either the start or after 6 days of addition of osteogenic medium, ALP activity was significantly increased at day 6 in the cultures treated with PTHrP (1-36) and at day 18 when that peptide was add from days 6 to 18 of osteogenic induction (Figure 2A). Moreover, a significant increase in ALP mRNA levels was detected in the latter cells, compared with those in untreated cells at day 18 (Figure 2A). This was associated with a weak increase of runx2 gene expression 
A
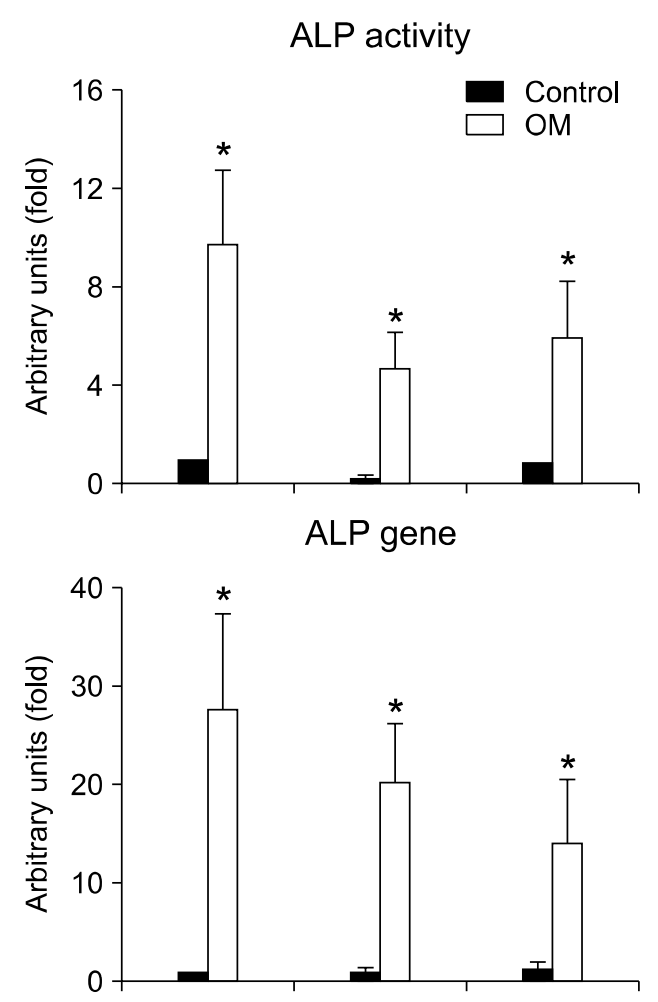

RUNX2 gene

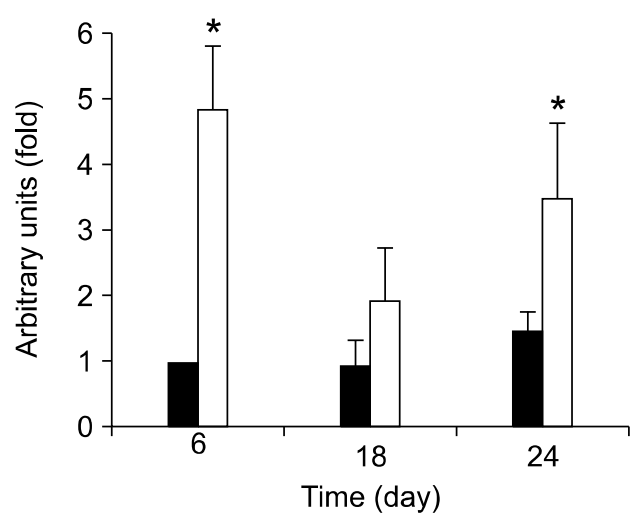

B
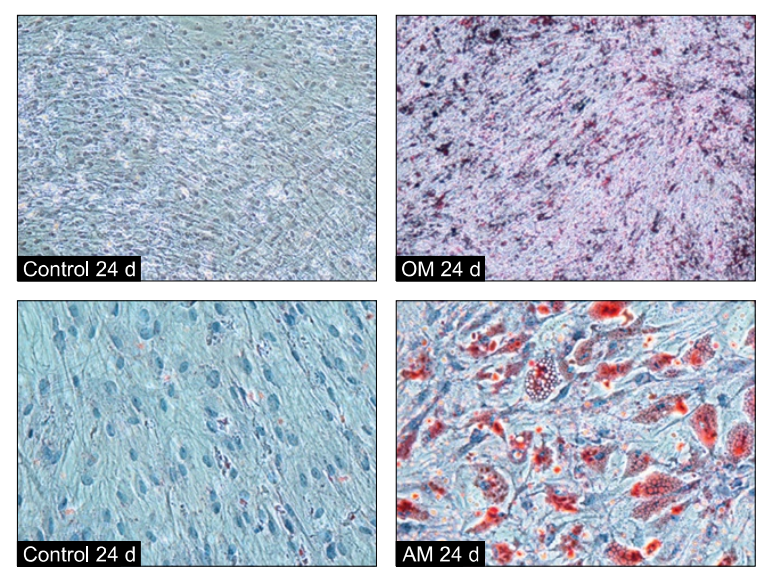

C

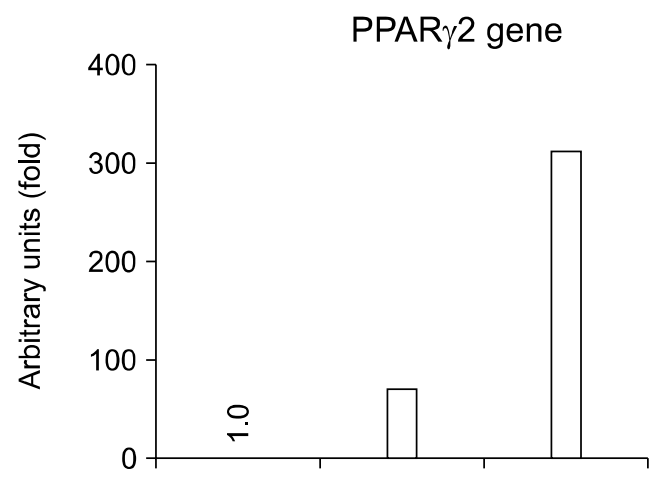

LPL gene

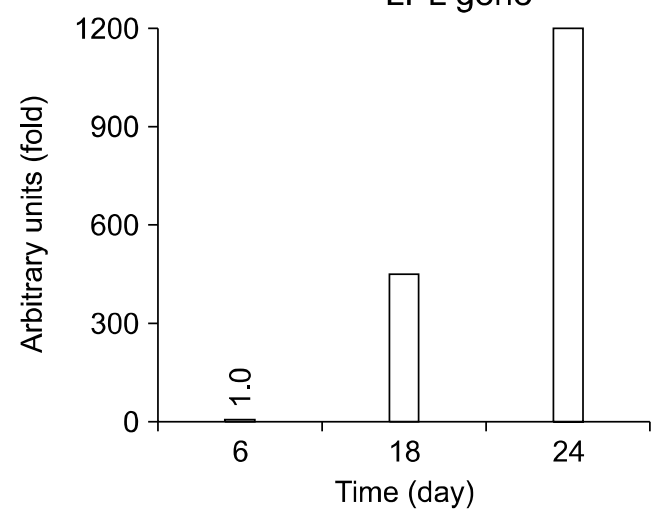

Figure 1. Expression of osteogenic and adipogenic markers in human MSCs grown for 24 days in osteogenic medium (OM) or adipogenic medium (AM). (A) ALP activity and gene expression of ALP and RUNX2 in control cell cultures and in those induced to osteoblasts at days 6, 18 and 24 . (B) Representative alizarin red staining from one MSC culture grown in OM or basal medium (control) for 24 days (upper panels) and oil red staining showing fat vesicle formation in MSC cultures maintained in AM or basal medium (control) for 24 days (lower panels). (C) Gene expression of PPAR- $\gamma 2$ and LPL in MSCs grown in AM at days 6, 18 and 24. Data represent the mean increase over control at day 6 (value $=1$ ) from 3 different human MSC preparations each one obtained from a different bone marrow sample $(A, C) .{ }^{*} P<0.05$ vs control.

induced by this PTHrP peptide within the same time period (Figure 2A). On the other hand, PTHrP (107-139) significantly reduced the gene expres- sion of these early osteoblastic markers at day 18 of osteogenic induction in these cultures (Figure $2 A)$. These changes were no longer observed at 
A
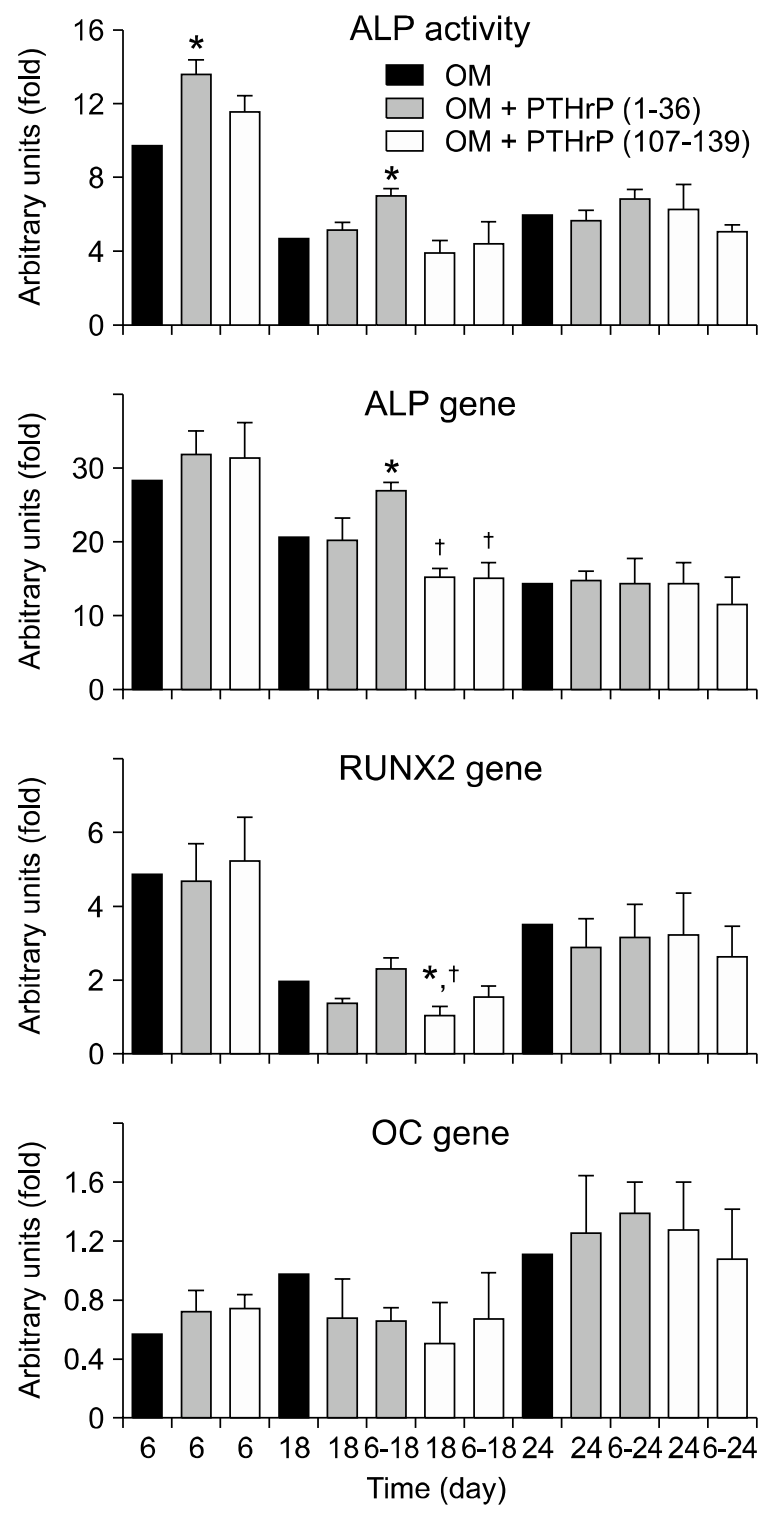

the end of the culture period (24 days). Moreover, OC gene expression, a late osteoblastic marker, was unaffected by any treatment pattern with these peptides throughout the period of study (Figure 2A). Moreover, these PTHrP peptides failed to produce any significant change in mineralization in human MSCs after 24 days of osteogenic induction (Figure 2B).

As both PTHrP peptides mainly affected early markers of the osteogenesis, the expression of runx2 gene and alkaline phosphates was then analysed, as well as the alkaline phosphate activity at days 2 and 4 of the treatment with each of the peptides. The alkaline phosphatase activity did not vary between these two times in the cultures
B

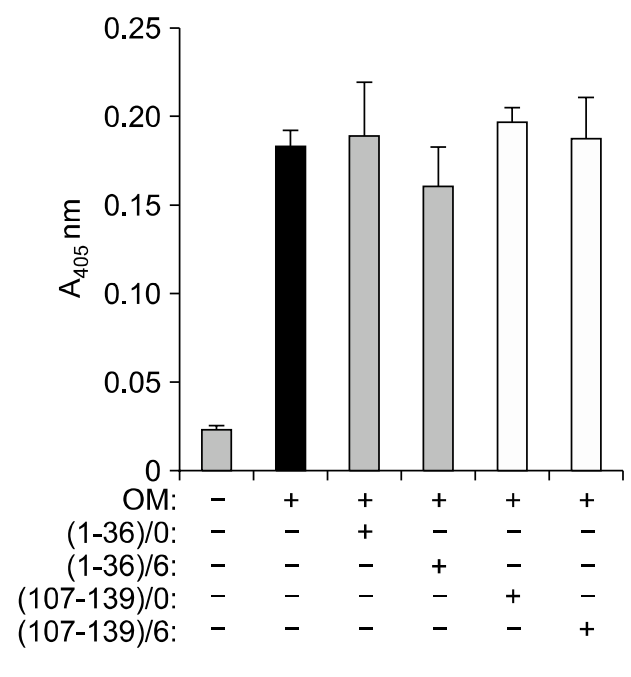

Figure 2. Effect of PTHrP (1-36) and PTHrP (107-139) on commitment of human MSCs to osteoblastic lineage. MSC cultures in osteogenic medium (OM) were exposed to $10 \mathrm{nM}$ of PTHrP (1-36) or PTHrP (107-139) from either day one or day six. (A) ALP activity and gene expression of ALP, RUNX2 and OC at different times of cell exposure to each PTHrP peptide or vehicle. (B) Spectrophotometric quantification of alizarin red staining in MSCs at day 24 after osteogenic induction in the presence or absence of PTHrP (1-36) or PTHrP (107-139) from either day one (/0)or day six (/6). Values are mean \pm SEM of 3 different cultures, each from a different subject, analyzed in duplicate. ALP activity and gene expression values were expressed as a fold change relative to those in undifferentiated MSCs (maintained in basal medium) at day $6 .{ }^{*} P<0.05$ vs corresponding peptide-untreated value. ${ }^{\dagger} P<0.05$ vs corresponding PTHrP (1-36)-treated value from day 6 to 18.

treated with PTHrP (1-36) or PTHrP (107-139) with respect to untreated cultures (Figure 3 ). However, the expression of the ALP gene at 4 days and that of the runx2 genes at 2 days increased significantly in the cultures treated with PTHrP (1-36). As far as the PTHrP (107-139) is concerned, it did not significantly affect the expression of either of these two genes.

\section{Effect of PTHrP (1-36) and PTHrP (107-139) on adipogenesis in human MSCs}

The expression of the adipogenesis-related genes PPAR $\gamma-2$ and LPL was found to decrease between 18 and 24 days of adipogenic induction in MSC 

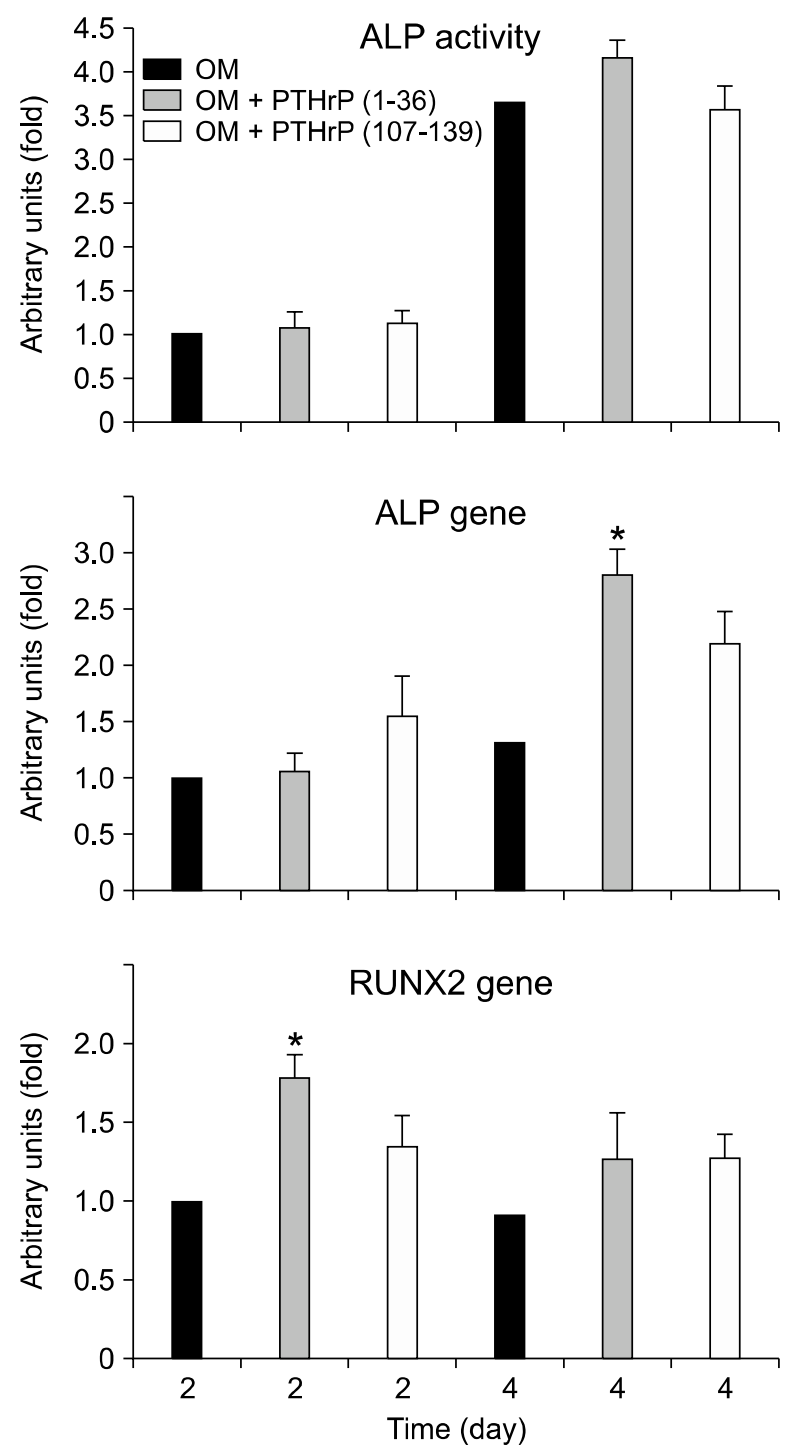

Figure 3. Effect of PTHrP (1-36) and PTHrP (107-139) on commitment of human MSCs to osteoblastic lineage. MSC cultures in osteogenic medium (OM) were exposed to $10 \mathrm{nM}$ of PTHrP (1-36) or PTHrP (107-139) for two or four days, and ALP activity and gene expression of ALP and RUNX2 were measured. Values are mean \pm SEM of 3 different cultures, each from a different subject, analyzed in duplicate. ALP activity and gene expression values were expressed as a fold change relative to those in osteogenic medium untreated at day $2 .{ }^{*} P<0.05$ vs corresponding peptide-untreated value.

cultures treated with PTHrP (1-36); whereas it showed a non-significant tendency to increase in those treated with PTHrP (107-139), compared to that in the untreated cells (Figure 4A). This different effect of these PTHrP peptides was observed even by delaying for 6 days their addition to MSC cultures after adipogenic induction (Figure 4A). This was also apparent by comparing the number of adipocytes and the content of fatty vesicles (as the amount of oil red stain) in these differently treated cell cultures (Figures $4 B$ and $4 C$ ). The increase of oil red stain in the cultures $\mathrm{PTHrP}$ (107-139) treated was significant (Figure 4B, down panel).

Given that PTHrP (1-36) exerts an inhibitory effect on adipogenesis, whilst PTHrP (107-139) tends to induce it, we set out to assess which effect would predominate if both PTHrP peptides were simultaneously added to MSCs in an adipogenic medium. With this aim, MSC cultures induced to adipocytes were treated as before from day 6 with either PTHrP peptide. Nine days later, PTHrP (107-139)-supplemented cell cultures did or did not receive the same concentration of $\mathrm{PTHrP}$ (1-36) for one more week. In those cultures treated with combined PTHrP (107-139) and PTHrP (136), PPAR $\gamma 2$ and LPL gene expression as well as the number of adipocytes and fat accumulation all decreased with respect to those treated only with PTHrP (107-139) (Figures 5A and 5B).

With the aim of analyzing the possible role of PTH1R in the inhibitory action of PTHrP (1-36) on adipogenesis, the PTH1R antagonist PTHrP (7-34) was used. Treatment of MSCs from day 6 up to day 22 with PTHrP (1-36) in the presence of this antagonist, at $1 \mu \mathrm{M}$, in adipogenic medium increase significantly the PPAR 2 and LPL gene expression and the number of adipocytes (Figures $5 \mathrm{~A}$ and $5 \mathrm{~B}$ ). But these values were still significantly smaller than those of untreated cultures.

\section{Changes in the PTH1R gene expression induced by PTHrP (1-36) and PTHrP (107-139) in human MSCs induced to osteoblasts or adipocytes}

We next examined the putative changes in the PTH1R gene expression induced by the different treatments in human MSCs during osteoblastogenesis or adipogenesis. PTH1R gene expression in these cell cultures showed a maximum at day 6 after induction to osteoblasts, followed by a later drop between 18 and 24 days. This pattern of expression was not significantly altered by the presence of either PTHrP fragment tested (Figure $6 \mathrm{~A})$. In those cultures induced to adipocytes, it is noteworthy that the PTH1R gene expression was considerably higher than that observed in the cells maintained in an osteogenic medium, mainly between 18-24 days of adipogenic induction. At this time period, PTHrP (1-36) inhibited this gene expression, whilst the C-terminal PTHrP peptide was inefficient in this regard (Figure 6A). Moreover, the inhibitory effect elicited by PTHrP (1-36) on PTH1R during adipogenesis was not significantly modified by the presence of PTHrP (107-139) in these cell 
A
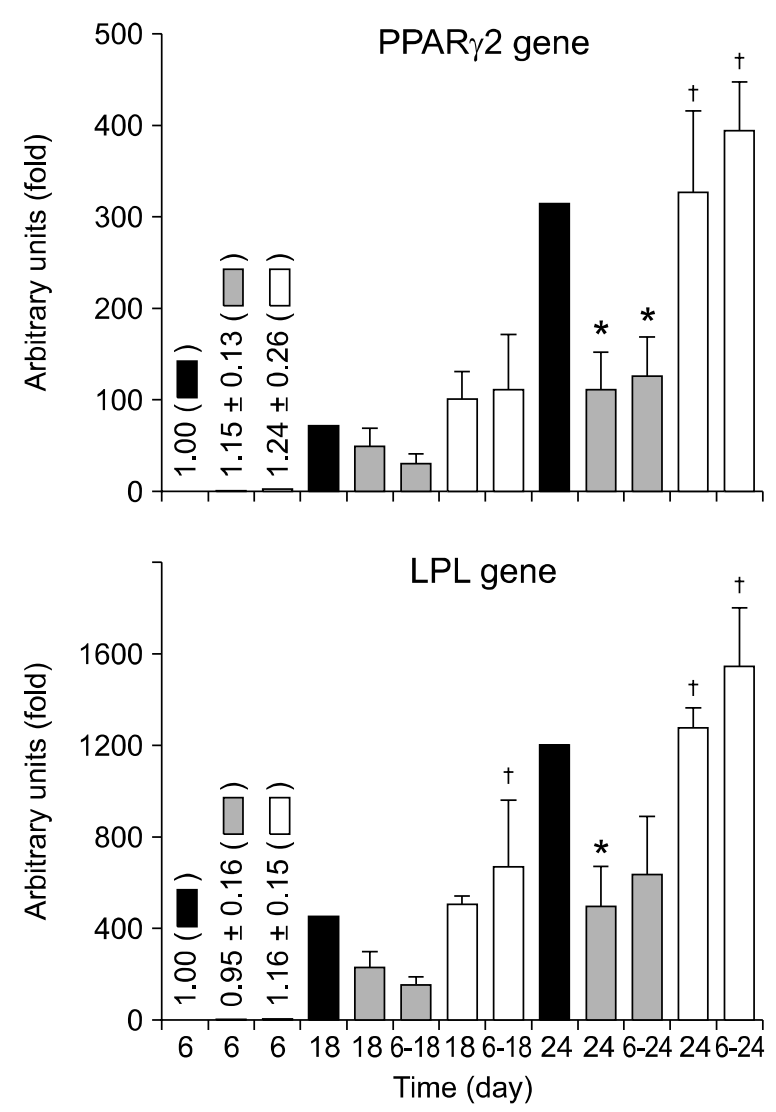

B
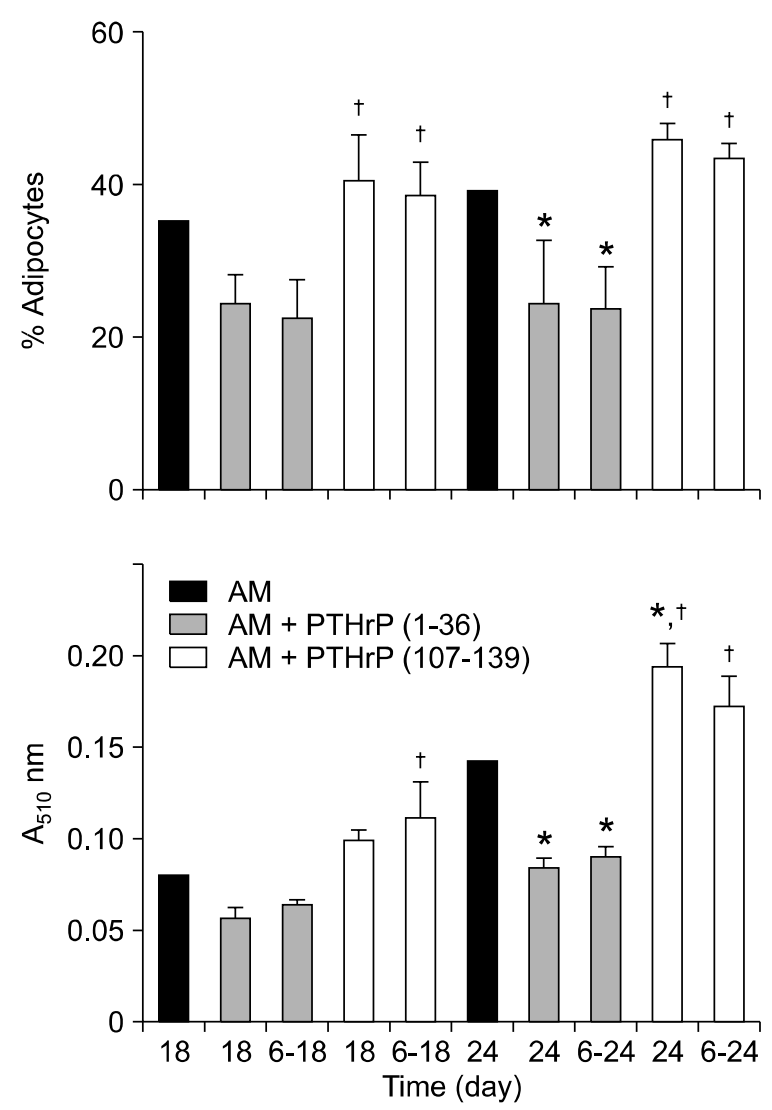

C
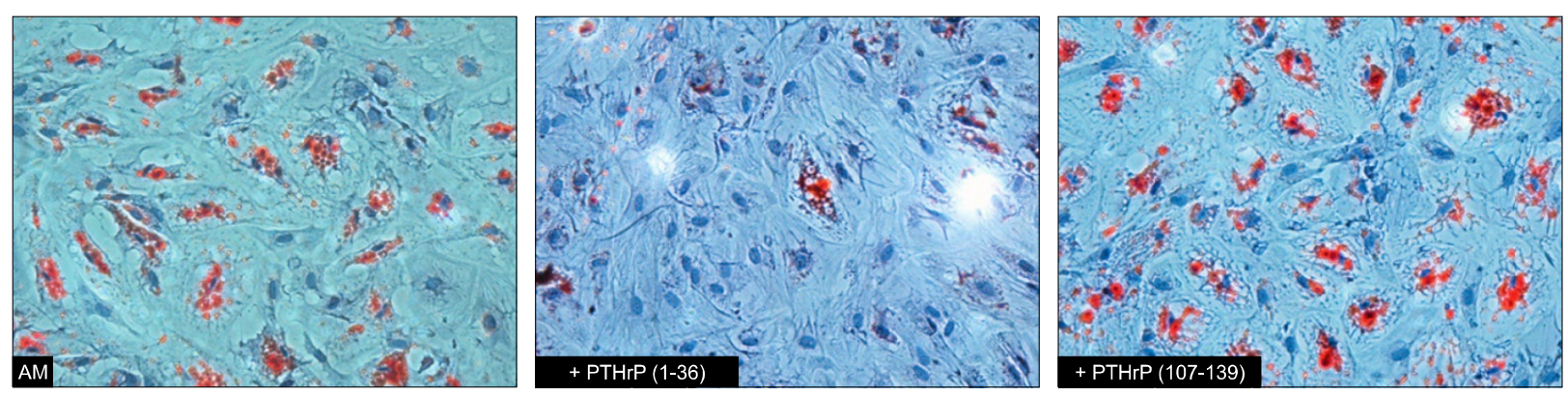

Figure 4. Effect of PTHrP (1-36) and PTHrP (107-139) on commitment of human MSCs to adipocytic lineage. MSC cultures in adipogenic medium (AM) were exposed to $10 \mathrm{nM}$ of PTHrP (1-36) or PTHrP (107-139) from either day one or day six. (A) Gene expression of PPAR- $\gamma$ and LPL at different times of cell exposure to each PTHrP peptide or vehicle. (B) Percentage of adipocytes and spectrophotometric quantification of oil red staining of fat vesicles in MSCs at day 24 after adipogenic induction. (C) Representative cultures induced to adipocytes and stained with oil red, treated or untreated with PTHrP (1-36) or PTHrP (107-139) are shown (magnification, $\times 200$ ). Values are mean \pm SEM of 3 different cultures, each from a different subject, analyzed in duplicate. The mRNA expression is expressed as a fold change relative to day 6 untreated MSC adipocyte induced as a reference $($ value $=1)$. ${ }^{*} P<0.05$ vs corresponding peptide-untreated value. ${ }^{\top} P<0.05$ vs corresponding PTHrP (1-36)-treated value.

cultures (Figure 6B).

\section{Discussion}

In this work, we have analysed the effect on MSC differentiation to osteoblasts and adipocytes of two PTHrP fragments, $\mathrm{N}$ - and $\mathrm{C}$ - terminal, that have different cellular receptors.

Recent studies indicate that endogenous PTHrP acts as a potent anabolic factor in fetal and adult bone (Strewler, 2000; Miao et al., 2004, 2005). In 
A

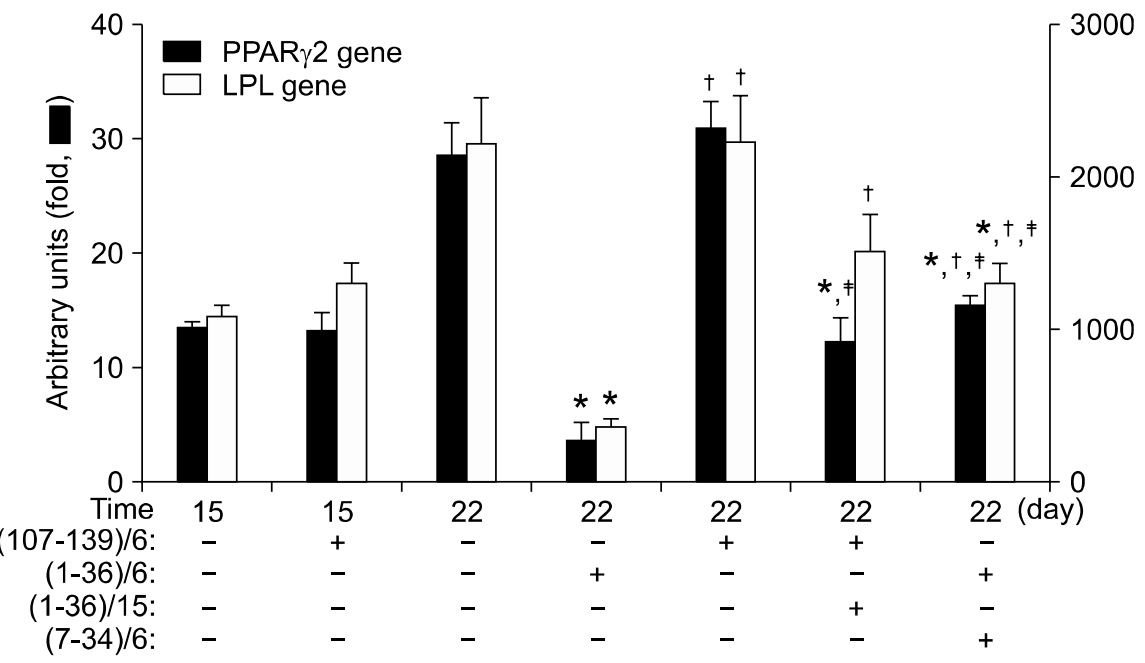

Figure 5. Effect of the PTH1R inhibitor PTHrP (7-34) and the pretreatment with PTHrP (107-139) on the adipogenic inhibitory effect of PTHrP (1-36) in human MSCs. Cell cultures in adipogenic medium (AM) were exposed to PTHrP (1-36) or PTHrP (107-139) (at $10 \mathrm{nM}$ ), from day 6 up to day $22((1-36) / 6$, $(107-139) / 6)$. At day 15, the same concentration of PTHrP (1-36) was added to some cultures $((1-36) / 15)$ which had been pre-treated with PTHrP (107-139) for one more week. Some PTHrP (1-36)-treated cultures were also treated with PTHrP (7-34), at $1 \mu \mathrm{M}$ added 30 min before, from day $6((7-34) / 6)$. (A) Gene expression of PPAR- $\gamma$ and LPL at different times of cell exposure to each PTHrP peptide or vehicle. Gene expression of both genes was expressed as a fold change relative to that of the housekeeping gene GAPDH. (B) Number of adipocytes and spectrophotometric quantification of oil red staining of fat vesicles in human MSCs at day 22 after adipogenic induction. The values are expressed as relatives to those in peptide-untreated cultures. Values are mean \pm SEM of 3 different cultures, each from a different subject. ${ }^{*} P<0.05$ vs corresponding peptide-untreated value; ${ }^{+} P<0.05$ vs corresponding PTHrP (1-36)-treated value; ${ }^{\ddagger} P<$ 0.05 vs corresponding value in cultures treated with PTHrP (107-139) only.

postmenopausal women with osteoporosis, daily PTHrP (1-36) administration increases trabecular bone mineral density, apparently at the expense of an increase in bone formation without significant changes in bone resorption (Plotkin et al., 1998; Horwitz et al., 2003). However, the true molecular mechanisms associated with the osteogenic action of this PTH-like fragment of PTHrP - in contrast to those of PTH (Goltzman, 2008) - have not been explored much. In the present study, exposure of human MSCs to PTHrP (1-36) in an osteogenic medium since day 6 increased the expression of some early osteoblastic markers. However, this effect was no longer present at the end of the study (day 24). This might be related to the current notion, based on studies in various osteoblastic cell preparations, that the anabolic effect of the $\mathrm{N}$-terminal domain of PTH and PTHrP seems to depend on both exposure time and the cell differentiation stage (Schiller et al., 1999; Fujita et al., 2001; Krishnan et al., 2003; de Gortazar et al., 2006). On the other hand, this effect of PTHrP (1-36) was not found to be elicited by PTHrP (107-139) in human MSCs; in fact, the latter peptide transiently decreased RUNX2 gene expression at day 18 in these cells. However, neither PTHrP (1-36) nor PTHrP (107-139) affected OC gene expression or mineralization in human MSCs. These findings thus suggest that these PTHrP peptides may affect the earlier stages of osteoblastogenesis in human MSCs in different ways. This is also supported by the fact that PTHrP (1-36) increased in expression of genes runx2 and ALP at days 2 and 4 of treatment, whilst PTHrP (107-139) did not affect the expression of either osteogenic markers.

A previous report has shown that continuous exposure of either rat osteosarcoma UMR-106 
A

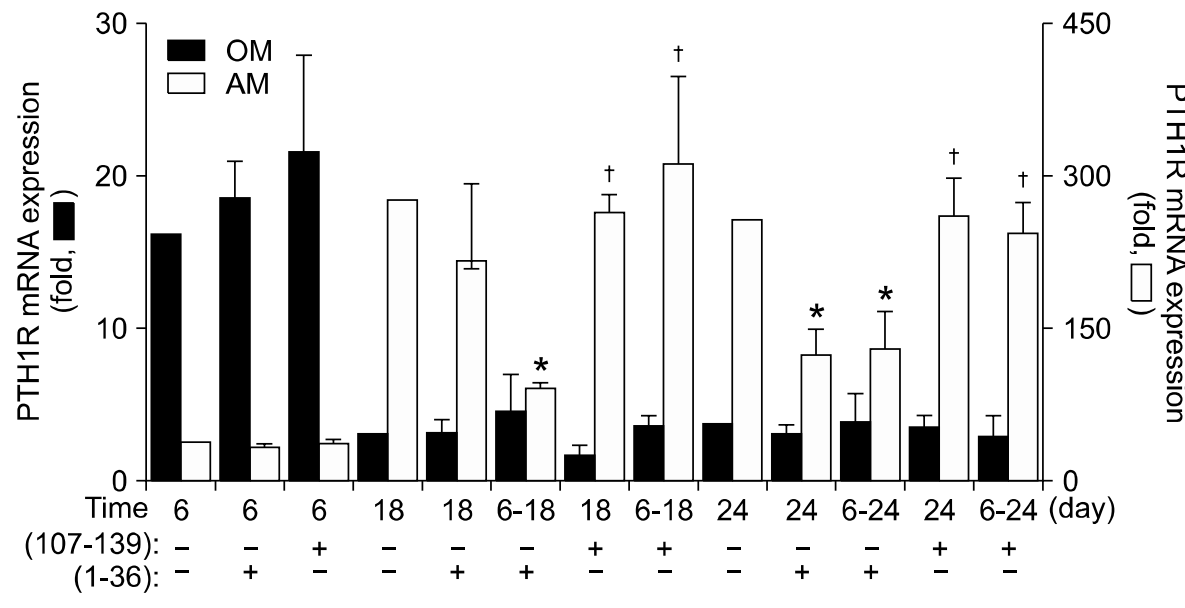

Figure 6. Relative expression of PTH1R gene in human MSCs during osteogenesis and adipogenesis. (A) Cells in osteogenic medium (OM) or adipogenic medium (AM) were exposed to $10 \mathrm{nM}$ of PTHrP (1-36) or PTHrP (107-139) from either day one or day six. (B) PTH1R gene expression at 22 days in MSC cultures exposed to adipogenic medium (AM) that were exposed to PTHrP (1-36) or PTHrP (107-139) (at $10 \mathrm{nM}$ ), from day 6 up to day 22 . At day 15 , the same concentration of PTHrP (1-36) was added to some cultures which had been pre-treated with PTHrP (107-139) for one more week. Values are mean \pm SEM of 3 different cultures, each from a different subject. Gene expression was expressed as a fold change relative to that in undifferentiated MSCs (maintained in basal medium) at day 6 (A), or to that in peptide-untreated cultures in AM medium at day 22 (B). ${ }^{*} P<0.05$ vs corresponding peptide-untreated value; ${ }^{\dagger} P<0.05$ vs corresponding PTHrP (1-36)-treated value; ${ }^{\top} P<0.05$ vs corresponding value in cultures treated with PTHrP (107-139) only.

cells or human osteoblast-like cells from trabecular bone explants to PTHrP (107-139) for several days inhibited ALP activity (Martinez et al., 1997; Valin et al., 1999). In contrast, it has been recently shown that intermittent but not continuous exposure of these cells or human osteosarcoma MG-63 cells during cell growth to this peptide for the first 6 to 24 $\mathrm{h}$ of a 48-h cycle stimulates osteoblastic differentiation (de Gortazar et al., 2006). Thus, different types of exposure to PTHrP (107-139) can stimulate or inhibit the osteogenesis.

Our findings demonstrate that the effects of PTHrP (1-36) and PTHrP (107-139) in human MSCs induced to adipocytes were still more different; the former peptide inhibited adipogenesis, but the latter showed a tendency to favor it. Moreover, this anti-adipogenic action of PTHrP (1-36) was somewhat attenuated but not abolished in the presence of PTHrP (107-139). Previous in vitro studies support an inverse relationship between PTHrP and adipogenesis. Thus, overexpression of
PTHrP or exogenous addition of its $\mathrm{N}$-terminal fragment inhibit adipogenesis in 3T3-L1 preadipocytes and pluripotential C3H10T1/2 cells induced to adipocytes (Chan et al., 2001, 2003). Moreover, a recent report has shown that transient $(1 \mathrm{~h})$ but not continuous exposure of human MSCs to $50 \mathrm{nM}$ PTH (1-34) inhibited their differentiation to adipocytes (Rickard et al., 2006). The finding that a short exposure to the latter peptide was as efficient as the continuous presence of PTHrP $(1-36)$, as shown here, to inhibit adipogenesis in these cells might be related to their different capacity to bind stably to different conformations of the PTH1R (Dean et al., 2008); considering that both peptides are likely to act through the PTH1R in human MSCs. Related to these in vitro data, a decrease in the expression of adipogenic genes in bone were found in osteopenic rats after daily administration of PTH (1-34) (Kulkarni et al., 2007). Furthermore, mice with heterozygous inactivation of the PTHrP gene have been shown to display 
low bone mass associated with increased bone marrow adipocytes (Amizuka et al., 1996). However, this increased bone marrow adiposity was absent in osteopenic mice with osteoblast-specific targeted disruption of PTHrP by using Cre/lox technology, which was thought to be accounted for by the timing of PTHrP ablation relative to the osteogenic and adipocytic programs (Miao et al., 2005). These in vivo results thus suggest that PTHrP could act on precursor cells before they are committed to either preosteoblasts or the adipocyte lineage. The present in vitro results in human MSC cultures further support the aforementioned in vivo findings, and provide a new rationale to explain the osteogenic effect of PTHrP (1-36) in osteoporotic postmenopausal women (Horwitz et al., 2003).

The important role of the PTH1R to negatively modulate adipogenesis in bone was further supported by the fact that its overexpression in mice was associated with an almost total absence of fatty cells in the bone marrow (Kuznetsov et al., 2004). In the present study, the PTH1R antagonist PTHrP (7-34) decreased the inhibitory effect of PTHrP (1-36) on adipogenesis, but was inefficient in completely re-establishing the PTHrP (1-36)inhibited adipogenesis in human MSCs. Although we used a concentration of PTHrP (7-34) which was 100 -fold higher than that of PTHrP (1-36), this might have been insufficient to block the PTH1R in these cells induced towards the adipocytic program. This is supported by the fact that in human MSCs, the PTH1R mRNA levels increased up to 300 times over those in non-induced control cell cultures by 18-24 days; possibly related to the high concentration of dexamethasone in the adipogenic medium, based on recent findings (Haramoto et al., 2007; Ahlstrom et al., 2009). In contrast, the PTH1R gene expression was found to increase in the first stages of osteoblastic differentiation -in agreement with previous data in primary mouse bone marrow cell cultures (Kuznetsov et al., 2004)-, decreasing thereafter, which might be consistent with a putative role of this receptor to commit human MSCs to the osteogenic lineage (Kuznetsov et al., 2004; Miao et al., 2005). The mechanism(s) whereby the PTH1R expression was higher in more advanced stages of adipocyte differentiation in human MSCs are presently unknown. However, this might be due to the concomitant increase of the PPAR $\gamma-2$ gene which could inhibit PTHrP production (Lappas et al., 2004), and this would in turn activate the expression of the PTH1R. In fact, ligand-dependent down-regulation of PTH1R is a well characterized event in osteoblasts and other cell types (AbouSamra et al., 1994; Du et al., 2000; Song et al.,
2009), and it might also well occur in cells of the adipocytic lineage.

In conclusion, our results demonstrate for the first time different effects of the $\mathrm{N}$ - and $\mathrm{C}$-terminal domains of PTHrP in the commitment of human MSCs. The continuous exposure of these cells to PTHrP (1-36) induced a mild osteogenic effect but inhibited adipogenesis, further supporting its potential use as a bone anabolic agent. On the other hand, a similar pattern of exposure to PTHrP (107139) seems to favor adipogenesis over osteogenesis in these cell cultures.

\section{Methods}

\section{Bone marrow donors}

The bone marrow donors were recruited by the Bone Marrow Transplantation Program of the Hematology Service at the "Reina Sofía University Hospital" (Córdoba, Spain). The experiments were performed with bone marrow obtained from three donors, two females and a male, aged 18, 23 and 31 years, respectively. All subjects gave their written consent.

\section{Bone marrow cell cultures}

Human MSCs were isolated from the bone marrow, following an optimized procedure based on previously reported methodology (Kotobuki et al., 2004; Casado-Diaz et al., 2008). In short, the bone marrow from each donor was centrifuged at $140 \times g$ for $10 \mathrm{~min}$ at $4^{\circ} \mathrm{C}$. The cellular fraction was seeded in two $75-\mathrm{cm}^{2}$ flasks (Nunc, Kamstrupvej, Denmark) in $\alpha$-MEM (Cambrex, East Rutherford, NJ) with 15\% FBS (Invitrogen, Carlsbad, CA), 2 mM UltraGlutamine (Cambrex), $100 \mathrm{U}$ ampicillin, $0.1 \mathrm{mg}$ streptomycin/ml and $1 \mathrm{ng} / \mathrm{ml}$ basic fibroblast growth factor (bFGF) (Sigma-Aldrich, St. Louis, MO) (culture medium), and maintained at $37^{\circ} \mathrm{C}$ in $5 \% \mathrm{CO}_{2}$. The medium was replaced every three to four days. When near-confluent cell colonies were observed, the cells were trypsinized and reseeded with the same culture medium at about 300 cells $/ \mathrm{cm}^{2}$ in $75-\mathrm{cm}^{2}$ flasks, using the same culture growing conditions previously described. These confluent cells were collected again by trypsinization. Between $8 \times 10^{5}$ to $10^{6}$ cells $/ \mathrm{ml} \quad \alpha-\mathrm{MEM}$ with $30 \% \quad$ FBS and $5 \%$ dimethylsulphoxide (Sigma-Aldrich) were collected in CryoTubes (Nunc), and stored in liquid nitrogen until their used.

\section{Osteogenic and adipogenic differentiation}

Cells were plated at 500 cells $/ \mathrm{cm}^{2}$ on 6 - or 12 -well plates (TPP, Trasadingen, Switzerland) containing culture medium supplemented with $10 \%$ FBS. When cells were $80 \%$ to $90 \%$ confluent, the medium was supplemented with either $10 \mathrm{nM}$ dexamethasone, $0.2 \mathrm{mM}$ ascorbic acid and $10 \mathrm{mM}$ $\beta$-glycerophosphate to induce osteoblast differentiation, or 
$0.5 \mu \mathrm{M}$ dexamethasone, $0.5 \mathrm{mM}$ isobutylmethylxanthine and $50 \mu \mathrm{M}$ indomethacin to induce adipogenesis. All these inducers were from Sigma-Aldrich.

\section{PTHrP (1-36) and PTHrP (107-139) treatments}

The human PTHrp (1-36) and human PTHrP (107-139) were synthetic peptides, kindly supplied by Pedro Esbrit (Laboratorio de Metabolismo Mineral y Óseo, Fundación Jiménez Díaz, Madrid), A.F. Stewart, M.D. (Division of Endocrinology and Metabolism, University of Pittsburgh School of Medicine, Pittsburgh, PA) and F. Roncal, Ph.D. (Proteomics Unit, Centro Nacional de Biotecnología, Madrid), respectively.

Human MSCs were induced to either osteoblasts or adipocytes, in the presence or absence (control) of each PTHrP peptide, at $10 \mathrm{nM}$. Six days later, some of these control cultures started to be treated with either PTHrP (1-36) or PTHrP (107-139), at $10 \mathrm{nM}$, in the presence or absence of the PTHrP antagonist, $\left[\right.$ Asn $^{10}$, Leu $^{11}, \mathrm{D}-\operatorname{Trp}^{12}$ ] PTHrP (7-34) amide (PTHrP (7-34); Bachem, Bubendorf, Switzerland), at $1 \mu \mathrm{M}$. When the cells were treated with PTHrP antagonist, this was added 30 min before peptide PTHrP. Cells were grown for 24 days, with fresh medium replacement every $48 \mathrm{~h}$. Some of those cultures which had previously been stimulated with PTHrP (107-139) for 15 days in adipogenic medium were subsequently exposed to the combination of both PTHrP peptides in the same medium up to the end of the study. Some cell cultures treated with the PTHrP peptides for 12 days starting at day 6 after induction of differentiation, based on initial experiments showing a response of osteoblastic makers at this time period (18 days).

\section{Alkaline phosphatase (ALP) activity}

Human MSCs maintained in osteogenic medium were lysed in PBS with $0.1 \%$ Triton $\times 100$ (Sigma-Aldrich), with the aid of a one-ml syringe plunger. Three to twenty $\mu$ of the resulting extract were mixed with $200 \mu$ of the ALP substrate solution ( $p$-Nitrophenyl Phosphate Liquid Substrate System ready-to-use, Sigma-Aldrich). The reaction mixture was incubated at $37^{\circ} \mathrm{C}$ for $30 \mathrm{~min}$, and then halted with $50 \mu$ of $3 \mathrm{M} \mathrm{NaOH}$. The reaction product was measured by absorbance at $405 \mathrm{~nm}$ on a GENios ELISA microplate reader (Tecan, Männedorf, Switzerland). The absorbance values were standardized for the total genomic DNA present in the extracts. The relative DNA amount of each sample was determined by quantitative real-time PCR (QRT-PCR), using GAPDH primers (Supplemental Data Table S1), with the QuantiTect SYBR Green PCR Kit (Qiagen, Hilden, Germany), using an Mx3005P QPCR System (Stratagene, La Jolla, CA).

\section{Reverse-transcription and real time PCR}

Total RNA was isolated with Tri-Reagent (Sigma-Aldrich) and treated with DNase I (Sigma-Aldrich). RNA quantitation was assessed at $260 \mathrm{~nm}$ with a ND-1000 spectrophotometer (NanoDrop, Wilmington, DE), and its quality (integrity) was checked on agarose gel electrophoresis. One $\mu \mathrm{g}$ of total RNA was retrotranscribed to cDNA using the iScript cDNA Synthesis Kit (Bio-Rad, Hercules, CA) in $20 \mu \mathrm{l}$. Real-time PCR was carried out in a LightCycler II real-time PCR thermocycler (Roche, Mannheim, Germany) with $1 \mu \mathrm{l}$ of cDNA and $10 \mathrm{pmol}$ of each primer corresponding to the tested genes (Supplemental Data Table S1), using the QuantiTect SYBR Green PCR Kit. The relative quantity of mRNA was calculated for each sample using the copy threshold (Ct) value, and normalized against GAPDH mRNA (housekeeping gene). The amplification profile included one cycle at $95^{\circ} \mathrm{C}$ for $15 \mathrm{~min}$ and 45 three-step cycles: $94^{\circ} \mathrm{C}$ for $15 \mathrm{~s}, 60^{\circ} \mathrm{C}$ for $20 \mathrm{~s}$ and $72^{\circ} \mathrm{C}$ for $20 \mathrm{~s}$. The results were generated and analyzed with LightCycler Software V 3.5, using the second derived method for the Ct calculation.

\section{Histochemical staining}

Mineralization of human MSCs induced to osteoblasts was tested using alizarin red staining. Thus, cells were fixed with $3.7 \%$ formaldehyde in methanol for $10 \mathrm{~min}$ and stained for $45 \mathrm{~min}$ with a mixture made up of $10 \mathrm{ml}$ of $1 \%$ (w/v in water) alizarin red plus one $\mathrm{ml}$ of $1 \%$ ammonium hydroxide. Then, the cells were washed with water, dried and visualized under a light microscope. The alizarin red precipitates were eluted with $10 \%$ acetic acid, neutralized with $10 \%$ ammonium hydroxide (all chemicals from SigmaAldrich), and the absorbance at $405 \mathrm{~nm}$ was measured, as previously described (Gregory et al., 2004).

Fat accumulation in human MSC cultures induced to adipocytes was tested using oil red staining. Cells were fixed as described above, washed with water, and subsequently stained for $15-20$ min with a mixture of $8.2 \mathrm{ml}$ of $0.3 \%$ (w/v in isopropanol) of oil red plus $6.8 \mathrm{ml}$ of distilled water. Cells were then washed with water, stained with hematoxylin and visualized under a light microscope (all chemicals from Sigma-Aldrich). The cells with lipid accumulation were counted in 10 different fields of each plate well, using contrast phase microscopy at $200 \times$ magnification. To quantify fat, oil red stain was extracted with isopropanol for $10 \mathrm{~min}$ at room temperature, and the absorbance of the resulting solution was measured at $510 \mathrm{~nm}$.

\section{Statistical analysis}

The data throughout the text are means \pm standard error of the mean (SEM). All $P$ values were calculated using ANOVA and Fisher's projected least significant difference (PLSD) test. A value of $P<0.05$ was considered significant.

\section{Supplemental data}

Supplemental Data include a table and can be found with this article online at http://e-emm.or.kr/article/article_files/SP42-2-02.pdf.

\section{Acknowledgements}

This study was supported by grants from "SANYRES XXI", CM0010/05, Grupo PAI CTS-413 (Junta de Andalucía, Spain) and Instituto de Salud Carlos III (PI052226, and RETICEF RD06/0013/1002). We thank Roger Bouillon 
their comments of the manuscript.

\section{References}

Abou-Samra AB, Goldsmith PK, Xie LY, Juppner H, Spiegel AM, Segre GV. Down-regulation of parathyroid (PTH)/ PTH-related peptide receptor immunoreactivity and PTH binding in opossum kidney cells by PTH and dexamethasone. Endocrinology 1994;135:2588-94

Ahlstrom M, Pekkinen M, Lamberg-Allardt C. Dexamethasone downregulates the expression of parathyroid hormone-related protein (PTHrP) in mesenchymal stem cells. Steroids 2009;74:277-82

Alonso V, de Gortazar AR, Ardura JA, Andrade-Zapata I, Alvarez-Arroyo MV, Esbrit P. Parathyroid hormone-related protein (107-139) increases human osteoblastic cell survival by activation of vascular endothelial growth factor receptor-2. J Cell Physiol 2008;217:717-27

Amizuka N, Karaplis AC, Henderson JE, Warshawsky H, Lipman ML, Matsuki Y, Ejiri S, Tanaka M, Izumi N, Ozawa H, Goltzman D. Haploinsufficiency of parathyroid hormonerelated peptide (PTHrP) results in abnormal postnatal bone development. Dev Biol 1996;175:166-76

Casado-Diaz A, Santiago-Mora R, Jimenez R, CaballeroVillarraso J, Herrera C, Torres A, Dorado G, QuesadaGomez JM. Cryopreserved human bone marrow mononuclear cells as a source of mesenchymal stromal cells: application in osteoporosis research. Cytotherapy 2008;10: 460-8

Chan GK, Deckelbaum RA, Bolivar I, Goltzman D, Karaplis AC. PTHrP inhibits adipocyte differentiation by downregulating PPAR gamma activity via a MAPK-dependent pathway. Endocrinology 2001;142:4900-9

Chan GK, Miao D, Deckelbaum R, Bolivar I, Karaplis A, Goltzman D. Parathyroid hormone-related peptide interacts with bone morphogenetic protein 2 to increase osteoblastogenesis and decrease adipogenesis in pluripotent $\mathrm{C} 3 \mathrm{H} 10 \mathrm{~T}$ 1/2 mesenchymal cells. Endocrinology 2003;144:5511-20

Cornish J, Callon KE, Nicholson GC, Reid IR. Parathyroid hormone-related protein-(107-139) inhibits bone resorption in vivo. Endocrinology 1997;138:1299-304

de Gortazar AR, Alonso V, Alvarez-Arroyo MV, Esbrit P. Transient exposure to PTHrP (107-139) exerts anabolic effects through vascular endothelial growth factor receptor 2 in human osteoblastic cells in vitro. Calcif Tissue Int 2006;79:360-9

Dean T, Vilardaga JP, Potts JT, Jr., Gardella TJ. Altered selectivity of parathyroid hormone $(\mathrm{PTH})$ and $\mathrm{PTH}$-related protein $(\mathrm{PTHrP})$ for distinct conformations of the PTH/PTHrP receptor. Mol Endocrinol 2008;22:156-66

Du P, Seitz PK, Cooper CW. Regulation of PTH/PTH-related protein receptor expression by endogenous PTH-related protein in the rat osteosarcoma cell line ROS 17/2.8. Endocrine 2000;12:25-33

Esbrit P, Alvarez-Arroyo MV, De Miguel F, Martin O, Martinez ME, Caramelo C. C-terminal parathyroid hormone-related protein increases vascular endothelial growth factor in human osteoblastic cells. J Am Soc Nephrol 2000;11:108592

Fenton AJ, Kemp BE, Kent GN, Moseley JM, Zheng MH, Rowe DJ, Britto JM, Martin TJ, Nicholson GC. A carboxylterminal peptide from the parathyroid hormone-related protein inhibits bone resorption by osteoclasts. Endocrinology 1991;129:1762-8

Fujita T, Fukuyama R, Izumo N, Hirai T, Meguro T, Nakamuta $\mathrm{H}$, Koida $\mathrm{M}$. Transactivation of core binding factor alpha1 as a basic mechanism to trigger parathyroid hormone-induced osteogenesis. Jpn J Pharmacol 2001;86:405-16

Goltzman D. Studies on the mechanisms of the skeletal anabolic action of endogenous and exogenous parathyroid hormone. Arch Biochem Biophys 2008;473:218-24.

Gregory CA, Gunn WG, Peister A, Prockop DJ. An Alizarin red-based assay of mineralization by adherent cells in culture: comparison with cetylpyridinium chloride extraction. Anal Biochem 2004;329:77-84.

Haramoto N, Kawane T, Horiuchi N. Upregulation of PTH receptor mRNA expression by dexamethasone in UMR-106 osteoblast-like cells. Oral Dis 2007;13:23-31

Hock JM, Gera I. Effects of continuous and intermittent administration and inhibition of resorption on the anabolic response of bone to parathyroid hormone. J Bone Miner Res 1992;7:65-72

Horwitz MJ, Tedesco MB, Gundberg C, Garcia-Ocana A, Stewart AF. Short-term, high-dose parathyroid hormonerelated protein as a skeletal anabolic agent for the treatment of postmenopausal osteoporosis. J Clin Endocrinol Metab 2003;88:569-75

Juppner H, Abou-Samra AB, Freeman M, Kong XF, Schipani E, Richards J, Kolakowski LF Jr, Hock J, Potts JT Jr, Kronenberg HM, et al. A G protein-linked receptor for parathyroid hormone and parathyroid hormone-related peptide. Science 1991;254:1024-6

Kotobuki N, Hirose M, Takakura Y, Ohgushi H. Cultured autologous human cells for hard tissue regeneration: preparation and characterization of mesenchymal stem cells from bone marrow. Artif Organs 2004;28:33-9

Krishnan V, Moore TL, Ma YL, Helvering LM, Frolik CA, Valasek KM, Ducy P, Geiser AG. Parathyroid hormone bone anabolic action requires Cbfa1/Runx2-dependent signaling. Mol Endocrinol 2003;17:423-35

Kulkarni NH, Wei T, Kumar A, Dow ER, Stewart TR, Shou J, N'Cho M, Sterchi DL, Gitter BD, Higgs RE, Halladay DL, Engler TA, Martin TJ, Bryant HU, Ma YL, Onyia JE. Changes in osteoblast, chondrocyte, and adipocyte lineages mediate the bone anabolic actions of PTH and small molecule GSK-3 inhibitor. J Cell Biochem 2007;102:1504-18.

Kuznetsov SA, Riminucci M, Ziran N, Tsutsui TW, Corsi A, Calvi L, Kronenberg HM, Schipani E, Robey PG, Bianco P. The interplay of osteogenesis and hematopoiesis: expression of a constitutively active PTH/PTHrP receptor in osteogenic cells perturbs the establishment of hematopoiesis in bone and of skeletal stem cells in the bone marrow. J Cell Biol 2004;167:1113-22 
Lappas M, Permezel M, Ho PW, Moseley JM, Wlodek ME, Rice GE. Effect of nuclear factor-kappa B inhibitors and peroxisome proliferator-activated receptor-gamma ligands on $\mathrm{PTHrP}$ release from human fetal membranes. Placenta 2004;25:699-704

Martinez ME, Garcia-Ocana A, Sanchez M, Medina S, del Campo T, Valin A, Sanchez-Cabezudo MJ, Esbrit P. C-terminal parathyroid hormone-related protein inhibits proliferation and differentiation of human osteoblast-like cells. J Bone Miner Res 1997;12:778-85

Miao D, Li J, Xue Y, Su H, Karaplis AC, Goltzman D. Parathyroid hormone-related peptide is required for increased trabecular bone volume in parathyroid hormone-null mice. Endocrinology 2004;145:3554-62

Miao D, He B, Jiang Y, Kobayashi T, Soroceanu MA, Zhao J, Su H, Tong X, Amizuka N, Gupta A, Genant HK, Kronenberg HM, Goltzman D, Karaplis AC. Osteoblastderived PTHrP is a potent endogenous bone anabolic agent that modifies the therapeutic efficacy of administered PTH 1-34. J Clin Invest 2005;115:2402-11

Orloff JJ, Reddy D, de Papp AE, Yang KH, Soifer NE, Stewart AF. Parathyroid hormone-related protein as a prohormone: posttranslational processing and receptor interactions. Endocr Rev 1994;15:40-60

Orloff JJ, Ganz MB, Nathanson MH, Moyer MS, Kats Y, Mitnick M, Behal A, Gasalla-Herraiz J, Isales CM. A midregion parathyroid hormone-related peptide mobilizes cytosolic calcium and stimulates formation of inositol trisphosphate in a squamous carcinoma cell line. Endocrinology 1996;137:5376-85

Plotkin H, Gundberg C, Mitnick M, Stewart AF. Dissociation of bone formation from resorption during 2-week treatment with human parathyroid hormone-related peptide-(1-36) in humans: potential as an anabolic therapy for osteoporosis. $\mathrm{J}$ Clin Endocrinol Metab 1998;83:2786-91
Rickard DJ, Wang FL, Rodriguez-Rojas AM, Wu Z, Trice WJ, Hoffman SJ, Votta B, Stroup GB, Kumar S, Nuttall ME. Intermittent treatment with parathyroid hormone (PTH) as well as a non-peptide small molecule agonist of the PTH1 receptor inhibits adipocyte differentiation in human bone marrow stromal cells. Bone 2006;39:1361-72

Schiller PC, D'Ippolito G, Roos BA, Howard GA. Anabolic or catabolic responses of MC3T3-E1 osteoblastic cells to parathyroid hormone depend on time and duration of treatment. J Bone Miner Res 1999;14:1504-12

Song GJ, Fiaschi-Taesch N, Bisello A. Endogenous parathyroid hormone-related protein regulates the expression of PTH type 1 receptor and proliferation of vascular smooth muscle cells. Mol Endocrinol 2009;23:1681-90

Strewler GJ. The physiology of parathyroid hormone-related protein. N Engl J Med 2000;342:177-85

Valin A, Garcia-Ocana A, De Miguel F, Sarasa JL, Esbrit P. Antiproliferative effect of the C-terminal fragments of parathyroid hormone-related protein, PTHrP-(107-111) and (107-139), on osteoblastic osteosarcoma cells. J Cell Physiol 1997; 170:209-15

Valin A, de Miguel F, Garcia-Ocana A, Esbrit P. Parathyroid hormone-related protein (107-139) decreases alkaline phosphatase in osteoblastic osteosarcoma cells UMR 106 by a protein kinase C-dependent pathway. Calcif Tissue Int 1999;65:148-51

Valin A, Guillen C, Esbrit P. C-terminal parathyroid hormonerelated protein (PTHrP) (107-139) stimulates intracellular $\mathrm{Ca}(2+)$ through a receptor different from the type 1 PTH/PTHrP receptor in osteoblastic osteosarcoma UMR 106 cells. Endocrinology 2001;142:2752-9

Wysolmerski JJ, Stewart AF. The physiology of parathyroid hormone-related protein: an emerging role as a developmental factor. Annu Rev Physiol 1998;60:431-60 